\title{
PRAÇA DÓBIO ZAINA: A HISTÓRIA DE UM ESPAÇO PÚBLICO
}

Rogério Penna Quintanilha, Amanda Dundi, André Damaceno, João Luís de Lima Júnior

Universidade do Oeste Paulista, curso de Arquitetura e Urbanismo, Presidente Prudente, SP. E-mail: arq.rogerio@gmail.com

\section{RESUMO}

O objeto deste artigo é a atual praça Dóbio Zaina, em Presidente Prudente, local do antigo Mercado Municipal da cidade. Apesar de sua grande relevância histórica, a história da praça foi pouco registrada pela historiografia urbanística, lacuna que o artigo pretende ajudar a preencher. Para tanto, foram consultados os acervos do museu histórico municipal e pessoas envolvidas com os diferentes momentos históricos da praça para que sua história possa ser registrada. $\mathrm{O}$ artigo termina com observações sobre seu estado atual e perspectivas para o futuro.

Palavras chave: Praça Dóbio Zaina, Presidente Prudente, Urbanismo.

\section{DÓBIO ZAINA SQUARE: THE HISTORY OF A PUBLIC SPACE}

\begin{abstract}
The object of this article is the current Dóbio Zaina square, in Presidente Prudente, site of the old Municipal Market of the city. In spite of its great historical relevance, the history of the square was little registered by the urban historiography, a gap that the article intends to help fill. For this purpose, the collections of the historical museum and people involved with the different historical moments of the square were consulted so that their history can be recorded. The article ends with remarks about its current state and perspectives for the future.
\end{abstract}

Keywords: Dóbio Zaina Square, Presidente Prudente, Urbanism.

\section{INTRODUÇÃO}

Hoje em dia, quem desce a avenida Cel. Marcondes em direção à APEA quase não nota a Praça Pioneira Dóbio Zaina. Na esquina com a Avenida Getúlio Vargas. Escondido atrás do feio e mal implantado edifício do Centro de Especialidades Odontológicas, a praça míngua pelo abandono e pelo descaso, transformado em pouco mais do que um estacionamento para os carros dos profissionais do núcleo. Muito pouco para um dos espaços públicos mais importantes e históricos de Presidente Prudente.

Nos anos de iniciais de Presidente Prudente, o Cel. Francisco de Paula Goulart, um dos fundadores da cidade, possuía uma chácara que viria a ser arrendada para o município e transformada em Bosque Municipal. No final da década de 1940 o bosque é loteado e transformado em um bairro residencial, o bairro do Bosque. Em seguida, é construído sobre a nascente do córrego Água do Bacarin, que ficava nos fundos do bairro, as novas instalações do Mercado Modelo Municipal.

O Mercado Modelo funcionaria no local por décadas, com diversos boxes de peixes, frutas, queijos e comidas. A qualidade dos produtos era destacada, e o Mercado foi uma referência para a cidade até ser desocupado nos anos 1990. Realmente, desde o final dos anos 1970 já havia a intenção de reformá-lo, com projetos elaborados para remodelamento dos boxes e principalmente da cobertura. Em 1993, no entanto, os comerciantes foram retirados repentinamente para uma reforma que nunca aconteceu. $O$ edifício foi demolido. 
Depois de algum impasse e de algumas propostas, o local foi transformado em uma praça de lazer, nomeada Praça Municipal Pioneiro Dóbio Zaina. O espaço público era bem utilizado: havia um espelho d'água, um teatro de arena, árvores e uma marquise, inicialmente pensada como sede da pinacoteca municipal, que recebia feiras de artesanato. Como de costume, a manutenção foi deixada de lado aos poucos. Pintura, bancos e arquibancadas foram se deteriorando, mas a praça resistia e continuava a receber pessoas e eventos. Até que no início dos anos 2000 a marquise foi ocupada por uma nova edificação, na realidade prevista no projeto original e não executada.

As salas construídas serviriam a repartições públicas, primeiro à Secretaria de Cultura e depois à Secretaria do Meio Ambiente. Em 2006 foi inaugurado o Centro de Especialidades Odontológicas, C.E.O.. A nova construção, no entanto, alterou radicalmente a dinâmica da praça que, escondida dos olhos da cidade, entrou em decadência. Atualmente, o descaso com a manutenção dá ao espaço um aspecto desagradável, escondendo as muitas camadas históricas contadas por um espaço tão importante para a cidade agora centenária.

\section{METODOLOGIA}

A pesquisa incluiu, em primeiro lugar, uma pesquisa prévia sobre o histórico da cidade de Presidente Prudente, para melhor compreensão de seu desenvolvimento urbano e do papel da região estudada no processo. Depois, foram feitas consultas ao acervo do museu histórico municipal para consulta de matérias jornalísticas e projetos relacionados ao local, o antigo mercado municipal e o terminal urbano proposto. Finalmente, foram feitas entrevistas com pessoas que de alguma forma participaram ou testemunharam a história da praça como o historiador José Caetano da Silva, a Dra. Maria Encarnação Spósito e a professora Edda Provana Bertoncin.

\section{RESULTADOS}

A formação das duas vilas históricas que deram início à cidade de Presidente Prudente, a Vila Marcondes e a Vila Goulart, é bastante conhecida e relativamente bem documentada por diversos autores. Os dois loteamentos iniciais, a leste e a oeste da estação ferroviária, tinham como propósito a venda de terrenos para a consolidação de pequenos núcleos urbanos capazes de fornecer suporte aos produtores agrícolas que se instalavam na região e seus idealizadores, os coronéis José Soares Marcondes e Francisco de Paula Goulart possuíam eles mesmos chácaras vizinhas a eles. De fato, é também conhecida a leitura segundo a qual a posição da fazenda de Marcondes, paralela à linha férrea, dificultou de alguma forma o crescimento da cidade naquela região embora certamente este não seja o único fator relacionado. A chácara Goulart, no entanto, implantava-se de forma diferente: logo diante da estação abria-se a av. Conselheiro Antônio Prado, ou av. Rio Branco como consta na planta de 1919, atual av. Washington Luís, com a vila Goulart a esquerda e a chácara Goulart a direita, de modo que a vila tinha caminho livre para se estender em dirEção ao leito do córrego do Veado, atual Parque do Povo, o que de fato aconteceu. Nos fundos da chácara Goulart ficava o brejo do Bacarin, nascente do córrego que receberia o nome de outra família que também possuía terras em suas margens.

A chácara Goulart manteve-se desta forma até a década de 1930 quando foi transformada em Bosque Municipal, como pode ser observado na planta da cidade elaborada pela Companhia Elétrica Cayuá em 1939 (SPOSITO, 1983). Ainda assim, consta que o bosque tenha sido efetivamente inaugurado em 1940, aproveitando a visita do Interventor do Estado Dr. Adhemar de Barros, apresentando uma área de quatro alqueires de mata nativa. O Bosque foi declarado utilidade pública, para fins de desapropriação pelo Decreto $n=9$, de 28 de setembro de 1943 . 0 investimento para tornar a reserva florestal em um parque público foi de $\mathrm{Cr} \$ 30.000$. No Bosque Municipal funcionavam escolas municipais e a escola rural Sud Mennuci, playground e ruas 
dotadas de bancos, bebedouros, iluminação e demais instalações. O Rotary Clube costumava realizar suas reuniões no local e os cidadãos frequentavam a área verde preservada.

Poucos anos depois, no entanto, Bosque Municipal passou a ser alvo de disputas judiciais pelo não pagamento por parte da prefeitura do arrendamento da chácara. O caso estendeu-se até 1948 quando o dr. Pedro Furquim, empossado prefeito, efetuou o pagamento e deu início ao loteamento da área. Derrubadas as árvores, o bosque foi convertido em um bairro residencial de alto padrão, o atual bairro do Bosque. Nos fundos do bairro, sobre o brejo do Bacarin, foi construído o Mercado Modelo que se tornaria referência no comércio de alimentos, frutas, legumes e peixes.

O primeiro Mercado Municipal de Presidente Prudente havia sido instalado em 1934 na atual av. Cel. Marcondes, onde hoje funciona o edifício do Corpo de Bombeiros. Com o loteamento do Bosque o mercado foi transferido na década de 50 para um novo edifício construído sobre o brejo do Bacarin. O Mercado Modelo possuía 60 boxes e era referência na venda de frutas de qualidade, mais caras e bonitas do que as encontradas nas feiras livres. Peixes e queijos também faziam a fama do local. Junto ao mercado funcionava um pequeno posto de gasolina.

No início da década de 80 o Mercado Modelo já apresentava sinais de desgaste, especialmente na cobertura, e são feitas várias tentativas de reforma. Em 1986 foi encomendado um projeto de reforma ao arquiteto D. Pantarotto pelo prefeito Virgílio Tiezzi. Um novo estudo foi realizado em 1991 pelo eng. civil Jorge Guazzi (Figura 1), a pedido de Paulo Constantino. As reformas, porém não foram executadas e o Mercado continuava a apresentar sérios problemas de estrutura até 1993 quando foi desocupado abruptamente. Os comerciantes tiveram que se retirar em poucos dias para que uma reforma fosse feita, mas nesse ínterim optou-se pela demolição do edifício e posterior transferência do Mercado para outra área junto ao córrego do Bôscoli, atrás do Parque de Uso Múltiplo, onde ainda se encontra.

O terreno do antigo Mercado ficou desocupado por alguns anos, cercado por tapumes, enquanto se encontrava para ele uma destinação. Uma das propostas incluía a construção de um terminal urbano pela Transportes Coletivos Brasília, empresa de ônibus que operava na cidade à época. O projeto chegou a ser divulgado no jornal e teve estudo arquitetônico inicial desenvolvido pelo arquiteto Cleyber Luciano Vieira (Figura 1). Além do terminal, o edifício contaria com uma nova sede para o Mercado Modelo no segundo pavimento, com boxes para o retorno dos comerciantes.

Figura 1: Projeto para a reforma do Mercado Municipal de 1991. (esq. Fonte: Museu Histórico de Presidente Prudente, 2016) e estudo para terminal urbano e mercado modelo na atual Praça Dóbio Zaina.

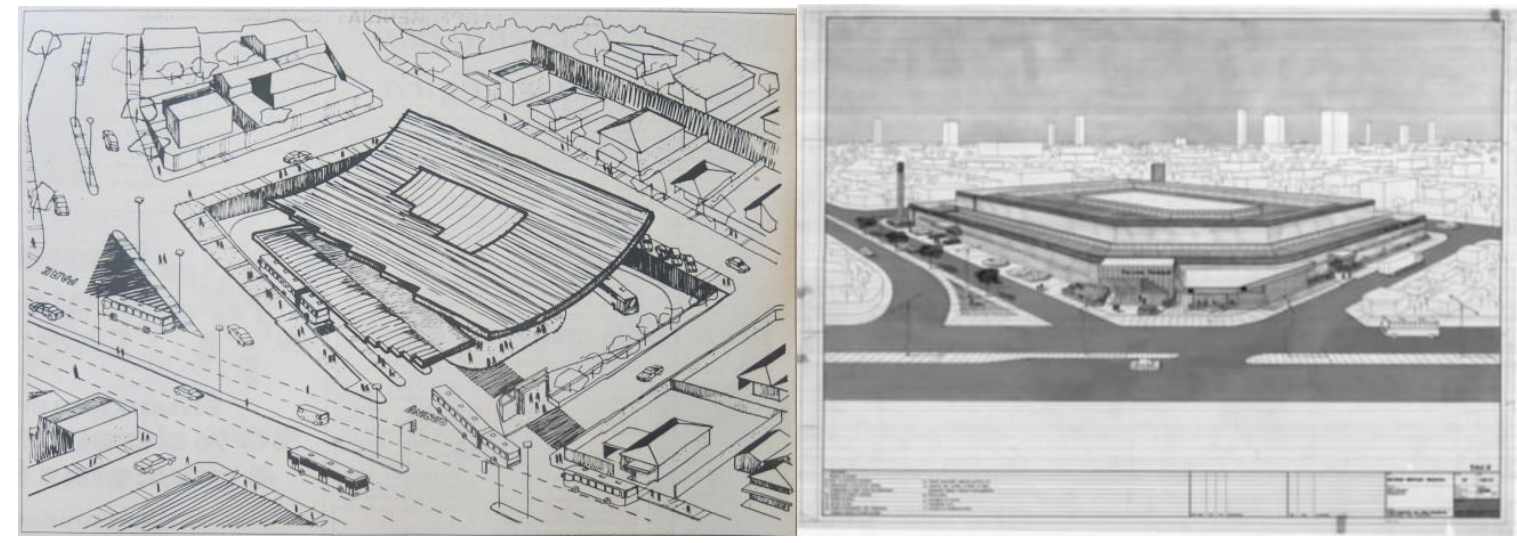

(dir. Fonte: O Imparcial, 1993) 
Com o fim da empresa de ônibus prudentina o projeto do Terminal Urbano foi abandonado e outra proposta foi elaborada: a construção de uma praça dedicada à cultura com teatro de arena e a sede da pinacoteca municipal, que a época funcionava no piso intermediário do edifício da biblioteca municipal no cruzamento das av. Washington Luís e Cel. Marcondes. Em 1996 foi inaugurada a Praça Pioneira Dóbio Zaina, nomeada pela lei 04339 de 15 de março do mesmo ano em homenagem a um comerciante italiano que chegou à cidade na década de 1920 e teve loja de roupas e armarinhos. A praça teve então sua fase áurea como espaço público.

O teatro de arena, denominado Profa. Sylma Fátima Bestestti Paccola pela lei 04445 de 28 de agosto de 1996, conta com pequena edificação que servia de depósito de coxias para shows de danças e apresentações de teatro e música. Uma banca de jornal na esquina da rua Paul Harris atraía o público nas manhãs de domingo. O desnível com a rua Anita Costa era resolvido por um jardim em vários níveis, incluindo um espelho d'água. Junto à av. Getúlio Vargas estava uma área mais arborizada.

A face da praça junto da av. Cel. Marcondes seria ocupada pela Pinacoteca Municipal sob um jardim suspenso que funcionaria como miradouro para a zona oeste da cidade. Seriam construídas salas de apoio, incluindo uma cantina, e espaço para exposições fechadas por blindex. No ano seguinte, no entanto, a diretora de artes visuais da prefeitura municipal responsável pelo acervo e arquiteta Edda Bertoncin, opôs-se à mudança por considerar que o projeto não apresentava condições mínimas para o funcionamento da pinacoteca, como área para reserva técnica. Além disso, o fechamento em blindex exporia as obras inadequadamente ao sol, comprometendo sua integridade. Assim, a pinacoteca não se transferiu e o espaço não foi fechado, criando uma pequena marquise. A Secretaria de Cultura ocupou as salas de apoio e passou a utilizar a marquise para promover feiras de artesanato e comidas. $O$ primeiro evento realizado foi uma festa italiana com música e comidas típicas. Aos finais de semana havia feira de artesanato e apresentações musicais nos sábados a noite e ocasionalmente também nas feiras de domingo.

Com o tempo, a feira passou a gerar menos interesse. O uso do teatro de arena era dificultado pelo calor e a feira de artesanato não oferecia novos produtos. Em 2004, a Secretaria do Meio Ambiente também mudou-se para o local, dividindo o espaço com a Secretaria do Meio Ambiente em 2006, o edifício foi ampliado para receber o Centro de Especialidades Odontológicas como parte do programa Brasil Sorridente do Governo Federal. Com 4 consultórios, salas de espera e recepção, laboratório e próteses e raio-x recebendo pelo menos 50 pacientes por dia e faz parte do conjunto de investimento que colocaram a cidade como referência entre os sistemas públicos de odontologia. A ampliação, no entanto, ocupou todo o espaço da marquise, alterando fortemente a dinâmica da praça.

A construção do Centro de Especialidades Odontológicas, a despeito de sua importância como programa de saúde pública, foi bastante prejudicial para a praça Dóbio Zaina como espaço público. Em primeiro lugar, evidentemente, a retirada da Secretaria de Cultura do local foi um desincentivo ao uso da praça como espaço de cultura. Os eventos rarearam. Além disso, a implantação absolutamente equivocada do edifício bloqueou simultaneamente o acesso e a visão da praça de seu lado mais movimentado, a av. Cel. Marcondes. A banca de jornal foi retirada levando consigo seu agradável movimento. Ao contrário do que seria esperada, a sala de espera do centro sequer se relaciona ou se abre para a praça, mas não passa de um ambiente escuro e sem janelas, dependente do ar condicionado, cuja entrada se dá por uma rampa lateral. Finalmente, a abertura de uma porta de serviço voltada para dentro da praça converteu o espaço público em estacionamento privado de carros e motos.

\section{DISCUSSÃO}


Infelizmente, a Praça Dóbio Zaina entra no ano de 2017, em que se comemora o centenário da cidade, em situação precária. O estado de abandono é praticamente total, salvo alguma limpeza na área do Centro de Especialidades Odontológicas. O espelho d'água está seco e quebrado. O teatro de arena pichado e as coxias, hoje depósito improvisado da prefeitura, têm os vidros quebrados. Os bancos de concreto quebrados e o guarda-corpo metálico de proteção da laje danificado. A vegetação, se não está abandonada, está longe de ser exuberante. Não é verdade que não existam usuários, ainda que não tanto quanto antes: não é difícil encontrar no local jovens, especialmente andando de skate. Alguns se escondem das aulas do colégio a poucas quadras. O ponto de ônibus e o C.E.O. tem movimento contínuo, mas que não chega a contaminar positivamente os demais espaços: a praça não é sequer um ponto de espera de consultas. Os carros dos funcionários do C.E.O. estacionados ocupam a praça e bloqueiam a passagem. A pintura de modo geral está bastante desgastada e há pichações em praticamente todas as paredes.

Além dos serviços de manutenção, o projeto da praça não pode ficar imune a críticas sobre o seu estado atual. Quantas vezes forem necessárias devemos repetir a lição de Jane Jacobs (2011) de que os espaços utilizados são os espaços seguros, e os espaços seguros são os espaços movimentados e visíveis. Este ensinamento teria evitado não só que o C.E.O. constituísse uma muralha entre a praça e seu principal ponto de visão e acesso, mas também que o depósito do teatro de arena fosse implantado inexplicavelmente a poucos metros do grande muro de arrimo entre a praça e a calçada, criando um ponto cego que certamente em nada contribui para a segurança ou limpeza da praça.

É evidente que uma leitura urbanística ampla da Praça Dóbio Zaina deve considerar seus aspectos históricos, como os tratados neste texto, localização, uso, função, entorno, clima, poluição sonora e todas as demais observações pertinentes ao desenho urbano. Somente este tipo de análise pode fornecer indicações para extrair da praça todo o seu potencial enquanto espaço público.

\section{CONCLUSÃO}

De modo geral, as praças públicas de Presidente Prudente entram no ano do centenário da cidade em situação lamentável. Não é verdadeiramente uma novidade, e nem acontece só nesta cidade. O declínio dos espaços públicos parece estar relacionado à ascensão dos espaços privados, como os shopping centers, e à privatização e exploração comercial de todo e qualquer evento de interesse. As praças, porém, são fundamentais para que Presidente Prudente reconheça sua própria história e preserve suas memórias, seu valor afetivo e suas singularidades. A praça Dóbio Zaina, como visto, possui uma rica participação nesta história que merece ser contada para que Presidente Prudente celebre seu centenário consciente de si mesma e de seu passado.

\section{REFERÊNCIAS BIBLIOGRÁFICAS}

BERTONCIN, E.; Entrevista concedida a Rogério Quintanilha. s/ed. 2016.

FARIA, L.; MOCCI, M; BORGES, M; BATTISTAM, M. Proposta de Intervenção na Praça Dóbio Zaina. s/ed. Presidente Prudente, 2016.

GEHL, J.; Cidades para Pessoas. São Paulo: Perspectiva, 2014.

GOOGLE EARTH; Imagens de satélite. 2016.

JACOBS, J.; Morte e Vida de Grandes Cidades. São Paulo: Martins Fontes, 2011. 3a ed.

LYNCH, K.; A Imagem da Cidade. São Paulo: Martins Fontes, 2011. 3a ed. 
MARTINS, D.; Projeto de Revitalização da Praça Dóbio Zaina. Trabalho de Conclusão de Curso de Arquitetura e Urbanismo. Universidade do Oeste Paulista, 2008.

MUSEU HISTÓRICO DE PRESIDENTE PRUDENTE.; Acervo. s/ed., 2016.

O IMPARCIAL.; Brasília apresenta projeto transformando o Mercado Modelo em terminal de ônibus. Presidente Prudente, 23 de janeiro de 1993.

SILVA, J.; Entrevista concedida a Rogério Quintanilha. s.ed. 2016.

SPOSITO, M.; O Chão em Presidente Prudente: a lógica da expansão territorial urbana. Dissertação de mestrado. Universidade Estadual Paulista Júlio de Mesquita Filho. Rio Claro, 1983.

SPOSITO, M.; Entrevista concedida a Rogério Quintanilha. s/ed. 2016. 